\title{
Rwandan Women in Higher Education: Progress, Successes, and Challenges
}

\author{
Elizabeth C. Reilly* \\ School of Education, Loyola Marymount University, Los Angeles, CA, United States
}

In nearly three decades since Rwanda's genocide and civil war, its education sector has undergone reconstruction to an unprecedented degree within higher education. While greater numbers of girls are attending university, and more women are becoming university faculty members, their status in educational leadership roles remains unclear. This qualitative investigation sought to present insight into four women who serve as professors and executive leaders within the higher education system by examining their progress, successes, and challenges. Four of the many insights that have emerged include women's smaller acceptance rate into higher education as undergraduates; the country's lack of Ph.D. programs, thereby requiring women to leave the country in order to obtain the terminal degree; disproportionate service expectations placed on women academics as compared to men that affect scholarly

OPEN ACCESS

Edited by:

Victoria Showunmi, University College London, United Kingdom

Reviewed by: Claudia Fahrenwald,

Pädagogische Hochschule Oberösterreich, Austria Pontso Moorosi, University of Warwick United Kingdom

*Correspondence: Elizabeth C. Reilly elizabeth.reilly@Imu.edu

Specialty section: This article was submitted to Leadership in Education, a section of the journal

Frontiers in Education

Received: 12 May 2020 Accepted: 05 August 2021 Published: 25 August 2021

Citation:

Reilly EC (2021) Rwandan Women in Higher Education: Progress,

Successes, and Challenges.

Front. Educ. 6:561508.

doi: 10.3389/feduc.2021.561508 output; and society's expectation for women's responsibilities as wives and mothers regardless of career responsibilities or status. To remedy these findings, further investigation can shed light on the reasons for low acceptance of women into the university; may lead to development of a strategic plan to address the lack of opportunities for students to enter graduate level education leading to the Ph.D.; and may address broader national policies that support women academics such as attention to child care and mentoring for promotion.

Keywords: African feminism, educational leadership and administration, gender equity, higher education - women in leadership, Rwanda, social justice and equity, women's rights

\section{INTRODUCTION}

Rwanda has the strengthened human capital, robust private sector and accountable institutions required to advance self-reliance.

Country Development Cooperation Strategy 2020-2025

She is Rwandan by birth. When she was a small child, Anne Clarisse's family lived just across the very porous border between Rwanda and Burundi, and movement back and forth did not even require a formal border crossing. Her father died when she was very young, so her mother had responsibility to raise her siblings and her. She had many brothers and sisters before the genocide-seven-but only two were left after the massacre. On the capriciousness of life and the inevitability of death, Anne Clarisse is sanguine even with tragedies she has endured. She says, "My mother was $82 \mathrm{yr}$ old when she died in 2015. I had been away for $6 \mathrm{yr}$ [pursuing my doctorate]. In my prayers I had always wanted to be close to her and I did not want her to suffer. Thank God, I was able to be with her during her last days. And the day she died, all three of us remaining children were lucky to be with her. You know, in this country, many people lost their 
parents, their loved ones, but they didn't have the opportunity to bury them. So, to be with her, we appreciate this."

This is how the story of Rwandan women in leadership begins-with remembrance of those loved and those lost, and of hope in spite of incalculable and unfathomable privations.

\section{BACKGROUND TO THE PROBLEM}

In 1994, Rwandans suffered genocide and civil war that left the nation in shambles. Numerous scholars and historians have documented the circumstances within the country that culminated in the state-orchestrated genocide (Taylor, 1999; Eltringham, 2004; Melvern, 2004; Prunier, 2009). Following the death of President Juvenal Habyarimana, a Hutu, in a suspicious 1994 plane crash, Rwanda's interim government directed the Hutu-dominated national army, militia groups, and citizenry to kill Tutsis and moderate Hutus (Melvern, 2004). Over an approximately 100-day period, Rwandans killed up to a million of their fellow citizens, including approximately three-fourths of the Tutsi population (Taylor, 1999). The genocide ended later the same year when the predominantly Tutsi Rwandan Patriotic Front, operating out of Uganda and northern Rwanda, defeated the national army and Hutu militias, and established an RPF-led multi-ethnic government whose goal was to establish national unity (Prunier, 2009).

Since 1994, the government has called for national reconciliation and abolished policies that had previously established and deepened ethnic divides. All references to ethnicity in written and unwritten official discourse, along with ethnic quotas for education, training, and government employment, ended. Today, the Constitution of Rwanda explicitly outlines policies for the eradication of ethnic, regional, and other divisions in society and promotes national unity (Thompson, 2014).

\section{STATEMENT OF THE PROBLEM}

With growing socio-political stability in Rwanda for the past two decades, a body of empirical research has emerged in a variety of disciplines within the social sciences and natural sciences. A comprehensive review of the literature, however, reveals that no studies have been published that address the role of women in educational leadership in Rwanda. Numerous reports from many organizations such as the United Nations (2006), USAID (2020), UNESCO (2007), UNICEF (2008), and the World Bank (2019) discuss either initiatives that were begun in the country or describe recommendations for the future related to security, governance, rule of law, human rights, and economic and social development.

A variety of reports do describe educational reform efforts-some of which include initiatives to train teachers and professors, to rebuild schools, to increase enrollment of children in school, and to identify problems with security in the nation's schools (Newbury and Baldwin, 2000; Obura, 2003; Republic of Rwanda Ministry of Education, 2008, 2012, 2013, 2018, 2019; Republic of Rwanda Ministry of Finance and Economic Planning, 2020). Some reports describe some efforts to train women in leadership skills, such as models of leadership, conflict resolution, and communication (Burnet, 2008).

Even so, little data exists to describe educational leadership in Rwanda, however Ministry of Education policies do describe management roles of headmasters (2018). No published empirical study to date until this one specifically addressed the status of women in educational leadership in either the Kindergarten through 12th grade sector or in higher education. This first study focused on the higher education sector and sought to provide insight into the status of women in educational leadership by examining their progress, successes, and challenges.

\section{PURPOSE OF THE STUDY}

The purpose of this investigation was to begin to remedy the lack of empirical data related to Rwandan women in higher education leadership by providing insight into their status. By interviewing both men who are qualified to provide observations into women's status and women who are higher education leaders, a portrait has begun to emerge from their past and present experiences, as well as from their hopes for the future.

1. Research Question.

This investigation sought to gain insight into the following question: What is the status of women in higher educational leadership in Rwanda-their progress, successes, and challenges?

\section{THEORETICAL FRAMEWORK AND RELEVANT LITERATURE}

This section explicates the theoretical framework that guided the investigation, as well as relevant background literature. I first present thinking about indigenous African feminist theory (IAF) and then examine these two themes in the literature related to African women in educational leadership: gendered leadership in the African context and African women in higher education leadership. As IAF is an entire field of theory with many perspectives and precepts, I present here some fundamentals and encourage more expansive and deeper examination of its application to Rwandan women in the future.

\section{African Women in Community: Indigenous African Feminist Theory}

Fundamental to the IAF project is decolonization (Wane, 2011). This perspective permits us to problematize and then address the concerns of whose knowledge is valid and whose voices shall be heard. African women acknowledge that their voices have and continue to be shrouded by thinking that came with their colonization over the centuries, and it therefore is essential to acknowledge when talking about IAF. Underlying this 
investigation is IAF theory as articulated by numerous scholars including Badejo, (1998), Elabor-Idemudia (2000), Goduke (2000), Mekgwe (2006), Dillard (2009), Fennell and Arnot (2009), Chilisa (2009, 2011), Chilisa and Ntseane (2010), Collins (2000 and 2009), and Wane (2011). I further apply the concept of indigeneity to IAF theory as elucidated by Bhola (2002), who makes the case for reclaiming culture and traditions that preceded colonial rule. He emphasized the necessity of embracing "African imagination, intellect, and existing material endowments" (Bhola, p. 1).

Overall, the scholars' work affirms girls' and women's "agency and resistance to often contradictory forms of patriarchal oppressions" (Chilisa and Ntseane, 2010, p. 618). The IAF model does not discount the role that motherhood, sisterhood, and friendship play in their understanding of who they are and the nature of their work in the world (Chilisa and Ntseane, 2010). Indeed, the recurring themes of IAF theory include Black women's gendered oppression, the role of family, their work and profession, and their activism (Wane, 2011).

Unquestionably, IAF theory challenges previous coloniality, interrogating the perspectives that are still woven through the tapestry of African civil society (Mekgwe, 2006). It does not, however focus solely on what the concept is not. For example, unlike Western conceptions of community, IAF theory invites us to be mindful of the interrelatedness of a woman to her community and that in the ideal, women thrive because of the relationship to the community (Badejo, 1998). In her work and that which precedes hers, Badejo recognizes the multiple roles women play in civil society today and found historically in its storytelling traditions and festivals "that place women at the center of the social order as custodians of the earth, fire, and water, and uphold men as the guardians of women's custodial rights" (Badejo, 1998, p. 94). One of the results of this work should be the transformation of civil society through the explorations of women's stories. It is their voices that led to the findings and discussion of ways to address the challenges and successes in Rwandan civil society.

\section{Africa, Women, and Educational Leadership}

In examining the literature about women in educational leadership, there is a propensity among Western scholars to frame the experiences of women globally through a homogenized lens, privileging those perspectives and theories since the preponderance of literature is Western in its origin and orientation. In an effort to decolonize my theoretical and methodological approaches to my work, I sought literature that was derived from or indigenous to Africa and applies indigenous African feminist perspectives. While literature on gendered leadership in sub-Saharan Africa is growing, it is slower on women in educational leadership, but I provide a review of some literature that may be relevant to African ways of knowing and being in two thematic areas: gendered leadership in the African context and African women in educational leadership.

With growing socio-political stability in Rwanda for the past two decades following the state-orchestrated genocide, a body of empirical research has emerged in numerous disciplines within the social sciences and natural sciences. The University of Rwanda reports that publication of peer-reviewed papers increased from 308 in 2014 to 2,096 total published in 2020 (University of Rwanda, 2020). While some of the in-country scholarship addresses some topics in the K-12 education system, none addresses higher education or higher education leadership specifically. A comprehensive review of the literature revealed that no studies have been published that address the role and status of women in higher education leadership in Rwanda. In approving this investigation, the Ministry of Education cited it as a landmark study, providing the beginnings of an empirical assessment of women's roles, which is a principal goal of the government and of the world community: to see expanded inclusion of women in all aspects of Rwandan society (Ministry of Education, 2008).

\section{Gendered Leadership in the African Context}

A number of scholars have provided a growing body of theoretical perspectives on and practical considerations for gendered leadership in Africa. Fourie et al. (2017), provide a review of scholarly research on African leadership from 1950 through 2009, summarizing $60 \mathrm{yr}$ of investigations. Their subsection on leadership and gender provides a broad review of work for many decades, with the limitation that the review ceases in 2009 , leaving a gap in the literature to the present day. The work of Gouws and Kotze (2007), Gouws (2008), and Nkomo and Ngambi (2009), for example, examine gender issues related to empowerment of women leaders; their approaches to creativity; their values; their leadership styles related to leader-member exchange theory (Gerstner and Day, 1997); the obstacles they face (Ntseane, 2009); Western bias of gender and gender relations; and their experiences of gender-based conflict.

The increased interest in research about leadership in Africa in general has increased overall each decade, with the largest number of studies from 2000 to 2009 approaching 60. Even so, between 1950 and 2009, only approximately 12 studies examined leadership and gender (Fourie, 2017). In general, literature since 2009 suggests all sectors of civil society throughout sub-Saharan Africa continue to suffer from a lack of gender equity (Cheeseman et al., 2017). While there is some progress, it continues to be uneven in terms of numbers, although some scholars suggest quality should outweigh quantity (Cheeseman et al., 2017). Fourie's 2017 investigation would benefit from updating, and perhaps should include published books on African leadership. A meta-analysis up to the present day would also enable a comparison of the gender themes from 1950 to 2009 to see if they have changed in any way. I describe in the next section the great increase in published scholarly work on women in educational leadership in sub-Saharan Africa since 2009 and it is not reflected in Fourie's investigation.

Scholarly sociological work from Rwanda may help to garner important insights into gendered leadership. I present here one example. Williamson Sinalo's work (2018), while not directly addressing women in leadership, does explore gender identity post-genocide and the experiences of women, along with the intersections of individualism, post-colonialism, and trauma in Rwanda. These several themes make evident the complexities of 
adding the intersection of women in leadership. So many conditions and considerations affect women in civil society, and gleaning insights via participants' personal narratives may provide entrée to the addition of women in leadership. Because the narratives, which are called testimonies, are publicly available in Kinyarwanda, the country's official language, through the Genocide Archive of Rwanda, they serve as a rich resource for considerations of women and their experiences or views of their role in leadership (Kigali Genocide Memorial, 2016).

\section{African Women in Educational Leadership}

Overall, much room remains for expansion of scholarly work in education on women in leadership in sub-Saharan Africa. There is a body of literature investigating women leaders in the K-12 space and it warrants mention since this is where the most research has taken place. The largest compendium of work appears in publications from the international collaboration of scholars and practitioners, Women Leading Education (2021), who document studies on women in educational leadership globally and who have hosted the special collection in which this article appears. These books and special collections in journals highlight many studies on women in educational leadership in sub-Saharan Africa. They include Sobehart, 2009; Grogan, 2015; Reilly and Bauer, 2015; Malachias et al., 2018; and McNae and Reilly, 2018.

For this review, I examined over thirty studies on women in educational leadership conducted in sub-Saharan Africa since 2006 (with one conducted in 2001) in K-12 education. The K-12 studies principally examine the role of the head teacher (frequently called the principal in Western settings). Overall, the preponderance of studies occurred in South Africa. (See, for example, Lumby, 2015; Lumby and Azaola, 2011, 2014; Lumby et al., 2010; Mathipa and Tsoka, 2001; Moorosi, 2010, 2015, 2020; Moorosi and Grant, 2016; Moorosi et al., 2016, 2018; Mpungose, 2010; Phendla, 2008.) Other studies occurred in Ghana (TagoeWilson, 2015), Nigeria (Deji and Makinde, 2006), Uganda (DeJaeghere et al., 2009, Kagoda, 2015; Kagoda and Sperandio, 2008; Sperandio, 2000; Sperandio and Kagoda, 2010; Raryera, 2015), and Zimbabwe (Chabaya et al., 2009).

From the studies I examined, I discerned the following general thematic strands: becoming and being a leader (motivations, career trajectory); leadership challenges such as stereotypes, discrimination, intersection of gender and class, race, and/or ethnicity; home life (spouse, motherhood, domestic responsibilities); leadership styles; and professional support such as mentoring and professional advancement. Some of the themes that have emerged from those studies may be considered relevant to women leaders in higher education in future studies. The investigations use principally qualitative methodologies, but do include mixed-methods approaches, as quantitative data can help to document demographic trends as well as overall perceptions of the women's experiences.

Here, I review some highlights of the findings. Overall, leadership challenges remain mixed from country to country in terms of experiences of discrimination from race, gender, tribe, or class. Each of these attributes warrants greater discussion, but that is beyond the scope of this paper, which is focused on women in higher education leadership. The intersectionality work colleagues and I have conducted (Moorosi et al., 2016, 2018), for example, examine issues of race and gender, and do call out the dual impact of these on every aspect of women's leading in education, while Chabaya et al. (2009) discuss persistent gender inequality in Zimbabwe. Lumby et al. (2010) provide a detailed discussion of the impact of gender on K-12 women principals.

Regarding home life, a number of studies touch on societal expectations for K-12 women leaders and family, and the impact this can have on motivation and career trajectory (Moorosi, 2015). Another topic some of the studies cover is the leadership style of women. Lumby and Azaola (2014) speak of a mothering style of leadership in South Africa, which they assert raises the hackles of Western feminists. This style may comport with some features of Western models of leadership, however, such as servant leadership, but would require further investigation and analysis (Nnameka, 1997; Steady, 2011). Finally, DeJaeghere et al. (2009) and others discuss professional support, such as professional training, that can help women achieve their goals.

There are fewer higher education leadership studies, but they examine a variety of aspects of women in leadership. Similar themes from these studies align with my work in Rwanda and with the findings of this study. The themes include enacting gender mainstreaming policies so as to address gender disparities in higher education in Botswana (Losike-Sedimo, 2017) and in Kenya (Odhiambo, 2011); mentoring higher education students in achieving leadership roles in Rwanda (Randell, 2009; 2018); mentoring women academics in leadership in Ghana (Wilson-Tagoe, 2015) and South Africa (Moodly, 2015; Moodly and Toni, 2017); and intersections of Rwandan women educational leaders with women leaders in Costa Rica and Afghanistan (Reilly, 2021).

The studies in higher education share two common features. First, all studies express the common theme of a lack of gender parity of women academics overall in higher education when compared to men, with the women also having limited representation in some disciplines, generally the natural sciences. The fewer number of women academics, then provides a smaller pool of women eligible for promotion into executive leadership roles. In some instances, as with Rwanda, holding the terminal degree remains an obstacle. Second, each emphasized the importance of policies, practices, and strategies that provide career development support for women academics (Moodly, 2015). Features vary, but many provide mentorship from senior academics principally focused on scholarship. In addition, the scholars emphasize that policies must mirror practices to support women leaders.

Overall, the scholarship on women in educational leadership in sub-Saharan Africa is still in its nascent stages. The K-12 education space does have a slightly larger body of literature, but most of it comes from South Africa. In addition, with the exception of the head teacher (principal), other leadership roles have not been investigated. In the higher education space, there is limited literature on women in educational leadership. There is much room for expansion in terms of the types of institutions investigated, the many topics that could be 
examined, and the numbers of countries engaged in understanding the progress, successes, and challenges of women in higher education leadership.

\section{METHODS}

\section{Research Design}

Through this qualitative ethnographic study, participants offered insights into their experiences as leaders and their perspectives on the progress, successes, and challenges of women in higher education leadership (Bernard, 2006). As described earlier, indigenous African feminism precepts drove the framing of the inquiry. Narrative inquiry as described by Clandinin and Connelly in several of their works served to frame my methodological approach. (See Clandinin, 2013; Clandinin and Connelly, 2000; Clandinin and Huber, 2010; Connelly and Clandinin, 1990; and Connelly and Clandinin, 2006.) I present here greater detail into the methodology of the study.

\section{Sample}

In this paper I highlight four women who are professors and educational leaders in Rwanda and were part of a larger study. The larger study included nearly 20 men and women in positions of higher education leadership or in positions of leadership in which they are qualified to comment on women in educational leadership. I typically include men who serve in executive leadership roles that include policy setting, hiring, supervision, and evaluation of women in leadership. One of the principal reasons for this is that in developing countries, men hold the vast majority of the most influential leadership positions.

This is the case with Rwanda beyond the large representation of women in the National Parliament; that governing body has been and remains an anomaly in terms of gender parity (Katengwa, 2010). The participants in this investigation included leaders from the University of Rwanda-the only public university-vice chancellors, provosts, deans, department chairs, directors, and professors in higher education and members of the Rwandan National government such as ministers and vice-ministers. All leaders lived within Kigali or traveled frequently to Kigali, the capitol of Rwanda, although this may not have been the city or country of their birth. Following the genocide, it became commonplace for Rwanda to hire men from other countries to serve in executive leadership positions among all professions.

\section{Assumptions}

I conducted this study with two, principal assumptions. First, I assumed that individuals who participated in this study were qualified to discuss and knowledgeable of the status of women in educational leadership in Rwanda. This was, in fact, the case. As men hold a disproportionate number of the executive leadership positions, their voices provided background context for the investigation and their views of women in leadership, coupled with their views on advocating for women's greater inclusion. Additionally, the women I interviewed either hold or have held executive leadership roles in a variety of contexts and thus provided extensive data on themselves and on their perspectives.

Second, I further assumed that individuals would provide an honest appraisal of their perspectives related to women in educational leadership in Rwanda. This assumption was based on my decades of training in and experience with conducting qualitative investigations where I can discern deception, were it to seem evident. I also understand how to seek a saturation level in interviewing, where a preponderance of recurring themes suggest little to no new data will emerge and any outlier views would perhaps be suspect. Finally, my experiences in conducting international research commenced in 1990 in the Moscow region during the collapse of the Soviet Union. Having first lived abroad during college and since then, traveled to over 50 countries, I have a high level of skillfulness in navigating cultures not my own and in gaining people's acceptance of the authenticity of my motives in speaking to them and in securing their trust. Because the focus of this paper is the Rwandan women who are educational leaders, I present more detailed background on my positionality in Supplementary Appendix C.

By triangulating the data with multiple interviews, document reviews, and my field notes, I am confident that participants were candid in their explanations and recollections. It was apparent to me that in a few cases participants were hesitant to speak truth to power, as there is an undercurrent of a level of concern among some that individuals might face possible retaliation if what they report might be viewed as critical of the status quo or of the federal government. This belief is not wholly without merit, based on the ongoing human rights issues I have documented in this paper. In the case of higher education, though, criticism framed as evidence-based critique, appears to be accepted by those in leadership.

\section{Limitations}

This study was limited to the geographical area of the capitol of Rwanda, Kigali. As a result, some findings may not be relevant to other areas of Rwanda, as socio-economic conditions vary greatly among them. The university has many campuses, and while faculty and leaders move between and among campuses, future investigations ought to explore the same issues on those campuses in other parts of the country. Finally, this study was limited to interviews with those individuals to whom I could gain access. Although many of the interviews were organized in the United States in anticipation of arrival in Rwanda, some of the individuals were not available once I arrived. My limited time in country also precluded meetings with some individuals, so return visits can address this limitation.

\section{Delimitations}

The study pertained to women in educational leadership in Rwanda and therefore the results may not apply to women in educational leadership in other nations; may not pertain to women in other leadership positions in the country; and/or may not pertain to men in educational leadership. Also, the findings may not apply to other universities in the country or campuses of the University of Rwanda that appear in other parts of the country. This delimitation can be addressed in future 
studies by broadening my interviews to other campuses, although policies of one apply to the other, which lessens the impact of this delimitation. In addition, as a targeted study, I invited participants with experience as a woman leader or qualified to comment, to recommend other individuals whom they felt were qualified to comment on women in higher education. Thus, snowball sampling led to additional participants.

\section{Types of Data}

Data included my field notes, recordings and transcriptions of each interview, and any documents available through public websites and that individuals provided to supplement basic information or to provide context for their organizations or programs. The interviews, though, were central to the investigation and they drove the analyses, with my field notes and other documents providing context.

\section{Means of Data Gathering}

I used several strategies to create field notes, to organize the interviews, and to review the documents I obtained. Overall, I applied the first two of Connelly and Clandinin's principles for narrative inquiry (1990), the "beginning the story" phase and the "living the story" phase (1990, p. 3-4.) The phase of beginning the story involved conducting background research broadly on Rwanda and on Rwandan education, along with research on prospective participants, including reading publicly-available documents such as biographies, profiles, and any published academic or other articles that they had authored. These notes became the basis for fieldnotes on each participant. The phase of living the story included conducting and recording the interviews, taking contemporaneous notes, and either writing or recording my impressions (Connelly and Clandinin, 1990).

\section{Protocol for Interviews}

I describe the protocol for the semi-structured interviews in greater detail in Supplementary Appendix A. I used three means of gathering data. First, I took or recorded detailed field notes that described the context for the interviews, as well as other pertinent information. Second, I conducted semistructured interviews individually in a place of convenience to the participants. All interviews took place either at their place of work or at the hotel where I was staying. These interviews were digitally recorded and then sent to participants for member checks. Third, I used other artifacts that participants provided that gave context for or amplification of their programs, initiatives, or organizations.

The interview questions that correlate with the research question are also included in Supplementary Appendix A. While the interviews followed the pattern of the questions as they were originally conceived, in nearly all cases, my interview was less a classic question and answer session and more of a conversation, covering topics of interest to them and expertise they wished to share. In many cases, I asked questions to deepen my understanding of my participants' experiences.

I was impressed with the level of candor that participants expressed with very sensitive topics. Every conversation was punctuated with statements around this broad construct:
Before the genocide and after the genocide. The genocide of 1994 remains the defining benchmark in the timeline of Rwandan higher education professionals and leaders.

\section{Data Analysis and Interpretation: Narrative Inquiry}

I first framed the analysis through the lens of a theoretical framework that embodies indigenous, African feminist precepts of the role of women in society. I applied it to their experiences in educational leadership. The precepts that served to underlie the analysis were women's experiences that explicated gendered oppression, their view of the role of family, work generally, and their profession overall, and their activism (Wane, 2011). An example of part of the coding process appears in Supplementary Appendix B. Broadly speaking, the categories I derived apply to any culture or civil society internationally, they do not imply a bias toward a particular perspective, and they reflect attributes of the United Nations Millennium Development Goals for gender parity internationally and the World Bank's goals through its Education for All initiative (UNESCO, 2007; World Bank, 2020, 2019).

With the feminist precepts in mind, I then used narrative inquiry as the methodological approach for the analysis of the data and for generating the synthesis of the progress made, successes achieved, and challenges faced among women in higher education leadership in Rwanda (Connelly and Clandinin, 1990). My intention was to memorialize and understand the experiences of the women through "a recursive, reflexive process of moving from field (with starting points in telling or living of stories) to field texts (data) to interim and final research texts [that] highlight ethical matters as well as new theoretical understandings of people's experiences (Clandinin and Huber, 2010, p. 20)." This method marries effectively with indigenous African feminist precepts.

Engaging in the third aspect of narrative inquiry, writing the story (Connelly and Clandinin, 1990), I first constructed the women's stories through the use of 1) field notes; 2) transcriptions of interviews; and/or 3) additional documents that the participants provided or I obtained through public websites. I wrote the first version of the narratives exactly as the women told their stories and later edited them slightly so as to tell the story in a coherent fashion. The rationale for this is that the interview protocol focused broadly on progresses, successes, and challenges, but the narratives generally made more sense unfolding in chronological order of life events. One example of a narrative appears in the findings, demonstrating how the narrative leads to the coding scheme.

Second, I identified topics and themes that emerged from the narratives by using an inductive analysis schema as follows: 1) scan the texts; 2) identify possible themes; 3) compare the data among the many texts; 4) consider the various ways the themes may be interrelated; 5) build concepts that the themes and data support; 6) consider the role that negative cases play in comparison to the themes and data; 7) present the summaries of each theme using the data-both paraphrased and in direct quotes. A summary of key aspects of the coding schema appear in Supplementary Appendix B. 


\section{Protection of Human Rights}

The Office for Human Research Protections of the United States Department of Health and Human Services, 2012 which describes laws, regulations, and guidelines regarding the protection of human subjects in those countries that presently have them. Rwanda is included in that document; therefore, additional approvals were necessary before commencing this study.

Rwanda's National Ethics Committee has guidelines for Human Subjects research related to bioethical considerations for the field of medicine, genetics, or biology (Ministry of Health, 2014). Additionally, for research related to education, the Ministry of Education has approval processes through, first, the Ministry of Health Ethics Committee, and second, through its review of the proposal, which I completed prior to seeking my university's final approval (Ministry of Education, 2014). This included garnering a supervisor at the University of Rwanda and completing that institution's approval process-a third aspect.

Following approval from Rwanda's Ministry of Education, which took nearly $7 \mathrm{mo}$, Loyola Marymount University's Institutional Review Board provided final approval to ensure that this study adhered to the guidelines for the protection of human subjects. Rwandans generally speak English, as well as Kinyarwanda and French. The Ministry of Education approved the study to be conducted in English and I was not required to provide the Letter of Informed Consent and other documents in languages other than English.

In summary, I completed five approval processes in order to conduct this investigation: requesting and obtaining a university sponsor, requesting and obtaining university research approval, requesting and obtaining Ministry of Health National Ethics Committee approval, requesting and obtaining Ministry of Education approval, and requesting and obtaining my university's Institutional Review Board approval. I complied with the laws, regulations, and guidelines for protection of human subjects in Rwanda, and with the guidelines that govern the protection of human subjects in the United States of America.

\section{Risk to Human Subjects}

I present a fairly detailed explanation of risk to human subjects because Rwanda is a post-conflict, post-genocide country which, while stable politically overall, has had external agencies identify as a nation with ongoing human rights challenges. One of the critical issues to discern with any human subjects research is whether the study could pose more than minimal risk to participants. When assessing this issue for research in Rwanda, I did take into consideration the current sociopolitical environment. At present, this nation is in reconstruction and has been for nearly three decades since its genocide and civil war. The reconstruction of education occurs through broad national plans from the Ministry of Education and in alignment with international projects such as the United Nations Sustainable Development Goals. At present, the country is not engaged in internal military conflicts that affect the daily lives of Rwandans, but incursions from Burundi and Democratic Republic of Congo remain an ongoing, frequent challenge.
Nevertheless, individuals who are engaged in the rebuilding of education in Rwanda-ministers of education, professors, school leaders, teachers, and even students-may endure high levels of stress. Therefore, given the level of risk participants in this study face on a daily basis by having chosen to rebuild education in the nation, I did not anticipate that they would face greater than minimal risk by consenting to an interview and answering the questions that will be posed. This proved to be the case overall.

I built a protocol into the Letter of Informed Consent that required each individual to decide whether or not his/her name would be used in publications or presentations. In the many years I have been conducting interviews in international settings, all but one individual has consented to my use of their names in presentations and publications so that they may receive attribution for their work as leaders. In Afghanistan, where I have previously investigated women in K-12 and higher education leadership, leaders insisted that I make their names public because of their significant roles in building civil society and their desire for recognition, regardless of the risk to their lives.

In the case of Rwanda, however, a few, but not the majority of individuals wished to remain anonymous. Even with political stability, reports emerge periodically about Rwanda regarding the status of human rights, suggesting challenges to freedom of expression, political pluralism, disproportionate use of force with Congolese refugees, and cases of unlawful detention, for example (Amnesty International, 2018, 2021; Tom Lantos Human Rights Commission, 2018; Human Rights Watch, 2020). Although nearly all participants explicitly stated that I could use their names, out of an abundance of caution, I elected to assign pseudonyms and, in some cases, disguise certain identifying features of their backgrounds.

\section{FINDINGS}

Through extensive document analysis and interviews with nearly twenty men and women qualified to provide observations into women's status, a portrait has begun to emerge. In this paper, I present analysis of the narratives of four of the women participants in the context of four, principal findings. These findings integrate salient quotes and summaries from the women. Each woman serves in an executive leadership role in the Rwandan government or at the University of Rwanda, and holds a faculty appointment at the university. I first present a story of one of the women leaders in higher education to demonstrate how I craft narratives of each participant prior to conducting the analysis. I then present and analyze findings that elucidate four aspects of the portrait.

\section{Marie Liliane: A Passion for Gender Inclusion}

Marie Liliane's early life provides an example of several benchmark events that led to the broader theme of gender inclusion. I provide here that portrait, which illustrates the life circumstances. These formative years led to her passion for girls 
and women in science, to her commitment to girls' primary education and women's access to higher education, and to her advocacy for women in educational leadership. Here is her story.

Born in a family of 10, Marie Liliane is the seventh child. She declares, "If I look at the way we were brought up, in our family, we did not have a distinction about gender" among the siblings, and her parents supported both boys and girls attending school. Each of the children, she recalls, were favorites of her grandfather, who had the means to help finance their education. During the genocide, which Marie Liliane refers to as "the terrible madness of our past," her grandfather lost two of his sons, one of whom was her father. Her grandfather "took the helm" in the aftermath to support the children's education, declaring there was no difference between the support either gender should receive.

While the genocide of 1992 continues to take center stage for its recent history, Marie Liliane explains that the 1960s were the time of the Rwandan Revolution where many Rwandans fled their homeland that created grave instability. At varying points, her family and she were refugees in Burundi, Congo, Kenya, Tanzania, and Uganda-wherever French was spoken. Even with the continual and profound instability that refugee status engenders, Marie Liliane was a successful student. Entering a Swedish-funded program that provided her the opportunity to seek teacher training, Marie Liliane earned her first degree in Kenya. Then, she qualified for admission to university, and attended University of Nairobi-Kenya's top institution-achieving her first degree in biochemistry and zoology. More degrees followed with a Fulbright award to study for her master's degree in the United States and later the opportunity to earn her doctoral degree in Belgium. While her studies were in French, the dissertation was published in English. Beyond her success as a scientist is her command of and fluency in multiple languages.

In 2009, she returned to Rwanda and had a teaching load at both the faculties of science and medicine at the University of Rwanda. She was likewise appointed to a newly-developed position in the Ministry of Education for Science, Technology, and Research, which she has developed from the ground up. Marie Liliane says, "I've got a passion for teaching-anything to do with education, I get carried away." In her work she is particularly focused on the inclusion of girls in science. She asserts, "There are so many of the stereotypes that science is not for girls."

Just as with her own childhood, she sees the link to the mindset of how children are raised. If the home environment and the parents encourage girls to engage with science, this can counteract the stereotypes of girls and women as incapable of professional positions in the science field. "Once they feel empowered, their performance is high, and I am happy about this," she asserts. Marie Liliane seeks to influence national educational policy to engage girls and women in science and, as a living example of a woman who has been successful in science, she frequently speaks to groups so as to shatter old belief systems.

\section{The Portraits' Four Aspects}

Four aspects form the findings of the overall portrait of the four women and are presented here. Findings suggest women's smaller acceptance rate into higher education as undergraduates results in fewer educated women prepared to serve in high-level roles in civil society. Furthermore, the country's lack of Ph.D. programs compels women to leave Rwanda to obtain a terminal degree, causing women to defy cultural norms and societal expectations as a wife and mother over commitment to self and professional aspirations. Third, if women do manage to garner a role in higher education, the institution places disproportionate service expectations on female academics as compared to men, affecting scholarly output. Finally, society's expectations for women's responsibilities as wives and mothers regardless of career responsibilities or status have shifted little postgenocide. I next consider each of these findings.

\section{University Acceptance Rate}

According to the University of Rwanda Statistics Office (2021), approximately $34 \%$ of its undergraduate and graduate students are female. In conversations with various higher education leaders, they cite varying reasons for the lack of gender parity in admissions. One leader stated that the problem begins in elementary school and becomes more pronounced by middle school, where girls carry disproportionate responsibilities for household duties when compared to boys.

As subjects such as mathematics become more challenging to children and they require more time to study and receive tutoring if necessary, girls' achievement gap widens because of the responsibilities they bear at home. By the time the girls take national entrance examinations for the University of Rwanda, their scores are less competitive with the boys and thus, fewer are admitted to the public university. Choices that remain for them for a higher degree are then limited to expensive private institutions, which are, in most cases, cost-prohibitive, and of varying quality.

Thus, the challenge women face in gaining educational leadership roles has its origins in elementary school. Fewer girls attain college degrees, leading to fewer women becoming university instructors, resulting in even fewer candidates who can attain tenure and the status necessary to achieve leadership roles in higher education.

\section{Terminal Degree Opportunities}

Approximately $19 \%$ of all university instructors possess a $\mathrm{Ph} . \mathrm{D}$. degree in their field. Fewer women instructors than this possess the terminal degree. To obtain a terminal degree, Rwandan men and women must leave the country. While partnerships with universities in countries such as Sweden are on the rise, a patriarchal culture such as Rwanda presents challenges for women seeking a doctoral degree. Women leaders such as Jeannette Francine cite the challenge in gaining the "approval" of their husbands to either leave their families behind, which creates great challenges for the sustainability of the family unit, or to take the entire family abroad for a number of years. Even so, Jacqueline Rose points out, "Whether the husband has to approve or not would depend on the woman's family and the structure of the patriarchy. I'm sure no husband would be opposed to that opportunity to take their children to nice schools and have all expenses paid." The short- 
term and long-term benefits are substantial and significant for all members of the family.

An additional result of the lack of Ph.D. holders among women is that women possess less training and experience in producing the scholarly work expected in their fields. Women cite little or inconsistent mentoring and professional development to remedy what is a broader problem for the entirety of higher education, but a particularly glaring one for women academics. Anne Clarisse mentioned that the university has committed to supporting women in specific. She remarks, "The result of a recent conference [the university hosted for all women academics] was a commitment to mentor rising scholars, develop research teams, and so on, but follow-up is necessary to see what progress will be made over time." Marie Rose adds, "Some women don't feel confident sometimes being involved in leadership, which is part of Rwandan culture. The person may not even know they are not confident." Mentoring opportunities could address this, she suggests. Finally, an ancillary issue is that English is the second language of Rwanda. As long as preeminence is still afforded Western journals and publishing houses that principally publish in English, women will require support not only for their research skillfulness but for academic endeavors executed in English.

\section{Successes and Challenges of Disproportionate Service Expectations}

The disproportionate expectation of girls' duties over boys' duties in support of the family and the priority placed on their fulfillment of these responsibilities is deeply embedded in Rwandan culture and long precedes a woman's professional life, if she has achieved one. This context helps provide a deeper understanding of the challenges that academic women in leadership face. Anne Clarisse, a senior lecturer and head of a center at the University of Rwanda, describes family life by pointing out that,

During our time, boys did not have the same status as girls-boys were highly considered and have the priority to go to school. I didn't see it in my family but I saw it among our neighbors. If they didn't have enough money, boys would go first and girls would remain at home. But I think in the minds of the parents, they didn't really think that much that "we send the boy and the girls stay home." It was more a case of who was more helpful. A girl would stay home, fetch water, clean the house, but when the boy stays at home, what would he do? This is because the domestic chores were different. They would look after the cows, but the girls cook, wash the dishes, etc., but the boy, no. So then sending the boy to school might then benefit the whole family.

7.2.3 Although education is considered free in Rwanda, there are ancillary fees associated with schooling that parents are required to pay. If a family, then, has limited monetary resources, Anne Clarisse makes it clear that a boy will be chosen to pursue education over a girl in the family. Moving many years forward, assuming a girl did receive an education, a college degree, and then did receive an appointment as a faculty member at the university, the expectation for a woman's role in and responsibilities for the family remain the same, and her professional responsibilities are often twice that of male professors.

One example is in the area of service to the profession. In Rwanda, as in most higher education settings globally, faculty are expected to engage in service to the profession, which is not traditionally or typically compensated work. Service to the profession is comprised of many roles, but for the purposes of this study, I focus solely on service in the department and university setting. Female faculty members at the University of Rwanda face vastly more responsibility for service requirements that do males. This is both a success and a challenge to their professional trajectories. The stated policy to promote gender equity for committee work is that $50 \%$ of each working group should be women (University of Rwanda, 2016).

On its face, equal representation of women in many aspects of governance is good news for women's voices and impact in the work of the university. The university has engaged in many changes since it became the one, public institution, including consolidation of programs, a new strategic plan, ongoing hopes to 1 day provide the Ph.D. in a variety of fields beyond a researchonly option, and more. Women's influence in forming the future of the university is important to achieving goals of gender equity and inclusion. Jacqueline Rose does point out, however, that to make the tasks even more palatable, even modest remuneration would go a long way. She advises that "additional incentives in the form of stipends would be of benefit to the family" and thus women would be willing to give up direct family time for indirect impact on their needs.

The level of engagement for women is not without a price, though. Since only $25 \%$ of the faculty are women (University of Rwanda, 2020), they are required to serve on twice the number of committees than men. Similar to the impact women faced on their academic achievement as girls because of the expectations of completing household duties, they now face double the service obligations in their university roles. Overall, the women cite the impact as untenable-that they have less time to produce scholarly products which result in promotion. Anne Clarisse remarks, "I think we all know the process we go through for promotions. Mostly it depends on qualifications and publications," but the time involved in service is substantial and without compensation. The lack of promotion opportunities, then, directly affects their ability to achieve leadership roles in higher education.

A second factor is that all employees of the University of Rwanda are public servants-employees of the government. They serve at the will of the Ministry of Education. Jeannette Francine described how she was clearly on a path for promotion in faculty rank, but with the departure of a center leader, she was unilaterally moved into that leadership role. While we might argue that the result was a leadership position for a woman, her superior moved her off the tenure line, and ultimately delayed her progress temporarily or permanently into higher level leadership roles in the university that require achieving the full professorship first. She states, "We can't expect to have more women in positions of leadership when we don't have them in schools or universities in the first place, because they are recruited from the faculty ranks." So, her assertion affirms the double impact of 
lower university admission of women in the first place, and then of the policies that affect their promotion if they ever manage to achieve an appointment as an academic.

Even though the women who are profiled in this paper have been unable to achieve promotion at the university beyond senior lecturer to associate- or full professor status, they have been able to achieve significant roles of influence in the federal government where substantive changes in gender perspectives have happened and continue to occur. Both Jeanette Francine and Marie Liliane have the potential for compelling impact nationally through their leadership roles in the federal government, which are not ceremonial, but instead highly influential positions of significance.

\section{Patriarchal and Societal Traditions}

Women educators and leaders each face traditional patriarchal and societal expectations of the role of women in civil society despite Constitutional guarantees and public policy that support gender equity. Women who remain unmarried for a variety of reasons face some benefits, but these come with societal liabilities. Several women in this study never married or had children and from my conversations with them, it was not a subject I could easily pursue. While they have greater flexibility to leave the country to pursue the Ph.D., and thereby possibly advance professionally, they face the stigma of remaining unmarried in a culture that expects traditional gender roles in the family-fulfilling the duties of a housewife and mother.

These duties require, as several women stated, that dinner is on the table at the appointed time, regardless of the responsibilities of their academic positions. Jacqueline Rose explains, "The other challenges such as promotion, require publications and research, and women face different challenges compared to men. For research, sometimes they cannot deliver like men because they have other family responsibilities and problems that require their attention. According to Rwandan culture, women are more involved in family issues." Additionally, care of the children is within the purview of women. All aspects of child-rearing, along with perpetuation of cultural norms requiring girls' substantiallydisproportionate attention to household chores, are enforced by men and by society.

Women do affirm that education is valued now more than ever-even among villagers, where there may be more responsibilities for agrarian activities. Anne Clarisse provides context by explaining, "In Rwanda, we feel that educating a child is the only investment you can make in the child. During our parents' time, they had cows. They had land. But as they grew up they noticed that they didn't have much to give to their children. Through education their children would get a bright future." She remarks that before education was compulsory, more girls would drop out at a young age and become housekeepers, providing much needed income for the families. More and more, though, parents recognize the shortterm monetary gain provides less income if a girl does not stay in school. So, the paradoxical consequence of girls staying in school longer is less in-home help for working mothers, increasing their burden. Even so, Anne Clarisse concludes, "This is the only property we have-knowledge. The only investment we can make in our children is studying so they can be responsible for their own lives." The benefits outweigh the liabilities.

Helping Rwandans to embrace more education for girls continues to be a challenge, but women leaders who are also scientists believe that challenging the gendered norms for subject focuses in school and in higher education, as well as in career choices for girls and women remain critical, as well. Anne Clarisse says that at the University of Rwanda, "There is no balance yet, but we are making progress. In the 1990s, I remember in my class, we were 16 students and only three females. I was in languages, and normally it is believed that girls go to languages, so if we were only three, in science, it was even more limited. I had a roommate who was doing physics, and in the 4-yr program, she was the only female." Marie Liliane summarizes emphatically that "innovation deserves to be a part of our culture. Yesterday's knowledge does not necessarily lead to tomorrow's solutions." As a scientist and leader in the federal government, her norm-challenging extends from macro-policy shifts to ongoing seminars on the importance of girls and women in science.

\section{DISCUSSION}

Fully one-fourth of every year in Rwanda focuses on the Commemoration Period-the time between May and July when the genocide took place over a quarter of a century ago. Public events, marches, and ceremonies take place countrywide for 3 mo. This amount of public recollection over its dark past affects how Rwandans view the world and the future. Every conversation with higher education academics and leaders, as well as government officials, includes depictions of events before and after the genocide. Euphemisms such as Marie-Christine's characterization of "the terrible madness of our past," punctuate conversations. The genocide seems inescapable and yet, "Rwanda First," is preeminent in people's discussions.

By government mandate, they are no longer Hutu or Tutsi; they are Rwandans first. Of course, in reality, this is not the case, and a visitor can easily infer from conversations and context what an individual's tribal affiliation was pre-genocide. If a Rwandan says, for example, that they have no living family members, it is entirely safe to assume that the individual is/was Tutsi and that their family was massacred. Critically significant, however, is that at present, the former tribal affiliations are less pressing societal issues than those of class and gender. This State-enforced remembrance each year does not necessarily include reflection on current events that may lead to greater gender equity, respect, and opportunities for girls and women. Furthermore, numerous international organizations produce yearly reports that indicate Rwanda must pay increased attention to human rights such as freedom of association, peaceful assembly, and expression; to violations such as enforced disappearances, deaths in custody, arbitrary arrests and detention; and to the rights of refugees and asylum-seekers (Amnesty International, 2021).

A 2017 United Nations report from the Committee on the Elimination of Discrimination against Women addressed successes, but highlighted numerous concerns regarding Rwanda's need to work on the UN convention on the 
elimination of all forms of discrimination against women (2017). The Committee recommended, for example, that "the State party repeal all remaining legal provisions that are discriminatory towards women and that it adopt comprehensive antidiscrimination legislation that prohibits discrimination on all grounds and encompasses direct and indirect discrimination in both the public and private spheres, as well as intersecting forms of discrimination against women" (United Nations, 2017, p. 3). Thus, even in policy and law, much work is to be done and therefore much work remains with implementation of practices that mirror the laws. Indeed, while this investigation instantiates the need for broader university and national policies that support the success of women academics, much fundamental work remains to be completed regarding gender equality more broadly.

\section{Moving the Needle on University Acceptance Rate}

The fundamental issue with the chronic, disproportionate representation of women as compared to men at the University of Rwanda is that the institution admits and then produces fewer highly-qualified women who are then competitive for professional positions throughout the nation generally and for academic appointments at the institution specifically. The university's admission of women for the first degree, the Baccalaureate, remain effectively unchanged at around $34 \%$. There is also still a propensity for women to be found in greater numbers in certain disciplines, such as in languages, and in far fewer numbers in others, such as in the sciences. In future studies I intend to examine the reasons for lower acceptance of women for the first degree as well as what leads to choices of certain disciplines over others. Based on some preliminary data from this original study, the problem begins when girls are in middle school, but more research is necessary. More detailed findings may lead to the development of a strategic plan or policy changes at the university or at the federal level.

\section{Expanding Terminal Degree Opportunities}

In the mid-2000s, the university had a partnership where women were able to pursue their doctoral degrees at a host of foreign universities to address the lack of opportunities for women to enter graduate level education leading to the Ph.D. At present this opportunity no longer exists. There are two ways Rwanda can address this. First, they can seek sponsors to revive the original model which provided women with the opportunity to be wife, mother, and scholar at the same time. Pursuing the degree at a foreign institution is considered a prestigious accomplishment and the degree establishes great credibility for woman and benefits to her family. I also spoke with the Vice Chancellor and Provost about pursuing Fulbright as an avenue for increasing the number of Ph.D.-holders in the country. Second, the institution must continue to seek its own Ph.D. degree offerings. They are working towards this, but I have been unable to ascertain their progress at this point. One consideration, however, is the liability of educating and then placing one's own degree-holders in one's home institution. The university must take this into account when considering this option. International, joint degree offerings, may help mitigate the liabilities of this avenue.

\section{Cultural Taxation: Disproportionate Service Expectations}

Women make it clear in the findings that unless scaffolded support is available to them in a variety of ways, they will continue to face challenges with promotion into higher level university leadership roles that require attaining the title of full professor. Stalling out at lecturer and senior lecturer is the rule, not the exception, and is exacerbated by the institution's unilateral imposition of leadership responsibilities, such as naming a woman as a center director, or the federal government appointing her to a new role. This is clearly good news and bad news. The positive effect is that the woman can have significant and substantive influence in the leadership role she undertakes. The far-reaching impacts of this are yet to be ascertained, but anecdotally, women in this study report this is a strength of these types of promotions. The negative effect is that it puts a halt to her research agenda, which affects promotion to associate or full professor, and thus to greater influence within the university. It also has an impact on the production of new knowledge in her field, which benefits not only her promotion efforts, but her discipline and also the university and its reputation in important ways. The women report that enhanced accommodations for their children in daycare and/ or preschool, as well as even modest financial incentives for their service and scholarship, allow them to achieve the dual goals of supporting themselves and their advancement as well as meeting their families' needs.

\section{Balancing Activism with Leaning into Patriarchal and Societal Traditions}

One of the striking differences between many Western feminist traditions and indigenous African feminism is that the women with whom I have spent time are decidedly not attempting to dismantle the cultural norms of the role of women in Rwandan society. They do not view their roles as wives and mothers to conflict with their professional aspirations or achievements. Rather, the women leaders ask for more scaffolded support to achieve the terminal degree, along with opportunities for mentoring and coaching in both leadership development and in scholarly productivity. Forming research groups and receiving small stipends for grant-seeking would also incentivize the women, as they see investing the additional effort would have direct benefits to their families. After just one, formal meeting that the university hosted for its women academics a few years ago, the women seized the opportunity to form an informal support network. The result was a flurry of inspiration to press on with their academic achievements and seek partnerships and support from one another.

While the women academics in this study do lean into many of the traditional Rwandan views of society and their roles, each of these participants expresses activism in a variety of ways. First, by nature of embracing their leadership roles, they engage daily in 
enacting substantive changes in policy and practice regarding girls and women in their field specifically and women in a variety of professions and in leadership more broadly. The women are not silent on issues of access to girls and women in education or the needs they individually have to advance the project of gender equity in Rwanda. Second, the women are not blind to the balancing act the Rwandan political landscape enacts on human rights. A country that spends one-fourth of each year in remembrance of its decimation of nearly a million of its fellow citizens serves as a continual reflection on the fragility of peace and the ongoing need for reconciling stability with greater freedoms for individuals. So-called "stability" can lead to institutional abuses if human rights become the target and extant humanitarian reports remind Rwanda to be mindful and address current challenges.

Another important finding was that the women leaders clearly reflect their values, beliefs, and praxis in accord with principles of indigenous African feminism. Although I did not explicitly pursue this line of inquiry with the women, their experiences and observations did address gendered oppression, the role of family, their work and profession, and their activism as evidenced in their stories. This suggests alignment with IAF, but I intend to establish a more cohesive conceptual model of IAF and then to reexamine the data sets through that lens. I also believe there would be great benefit to conducting meta-analyses of the literature of IAF, of gendered leadership in the African context, and of African women in educational leadership. This would permit a deeper understanding of the body of work in sub-Saharan Africa and help to situate future research from Rwanda and other countries in that context. It would also invite more systematic consideration of ways to enact indigenous African feminist principles and challenge colonialist values that are still deeply embedded in the entirety of sub-Saharan Africa.

\section{Broad Recommendations}

I conclude with some practical steps the university and government can take to address the four, principal findings.

1. Provide professional development and mentoring for women academics that support rigorous scholarship and a roadmap for promotion.

2. Examine the policy of unilaterally moving women academics from the academic track to positions that eliminate their progress on the tenure line.

3. Consider a different approach to service obligations that does not require women academics to engage in twice the amount of university service as men, but still invite their voices and impact.

4. Explore options for child care and children's education in close proximity to a women's job so as to support her familial obligations.

5. Continue to examine public higher education in relation to the challenges the United Nations Sustainable Development Goals raise that encourage or inhibit gender equity in Rwanda.

In addition, I invite these considerations for future investigation.
1. Continue inquiring into women in higher education leadership by expanding the study to other University of Rwanda campuses and to other institutions of higher education.

2. Explicitly examine the relationship between broad themes of indigenous African feminism and Rwandan women in higher education leadership.

3. Examine the relationship between the impact of the genocide on indigenous African feminism and Rwandan women in higher education leadership.

4. Expand the investigation and include any of the previous recommendations in a study of women in K-12 educational leadership and compare the findings between K-12 and higher education.

\section{SIGNIFICANCE OF THE STUDY}

In assessing benefits this research offers to Rwandan society and to the international field of women educational leadership, I present several implications. First, scholarly research within the field of education is much needed in Rwanda. One hallmark of a nation's rebuilding efforts is the degree to which scholars beyond its borders are interested in examining issues and establishing research agendas. This investigation may serve as example to other scholars worldwide of the benefits of engaging directly with the nation.

That said, the Ministry of Education's processes for foreign scholars seeking access should undergo a thorough review and steps made clear, streamlined, and uniform so as to encourage greater access and partnerships internationally. The $7 \mathrm{mo}$ it took for me to receive approval required countless emails and, ultimately, in-country support from an individual contact to determine the processes required to gain approval and to help shepherd each step. Second, it was difficult to fulfill the requirement of having a university sponsor, and then, once I did obtain one, great confusion over the individual's role and responsibilities. My sponsor initially expected compensation until I explained I was not being funded by anyone to conduct the study. Once in country, I never met the individual and they provided no support of any kind beyond lending their name on paper as sponsor. Finally, there was inconsistency between the process I experienced and that of my doctoral student, who was conducting a different study during the same time period. She faced additional obstacles and challenges to approval that I as a senior scholar did not face, including a mandatory, incountry appearance to make the case for her study before Rwanda's National Ethics Committee. Even with the numerous obstacles, though, once I met all requirements, Rwandans' warm welcome and gracious hospitality, their candor, and their level of engagement with the research made the many challenges worth the effort.

Second, few studies examine K-12 schooling in Rwanda and none have examined educational leadership broadly and higher education leadership specifically. While women have made positive strides in public service positions, where they 
represent over $60 \%$ of elected members of Parliament-and this achievement has attained international recognition-until this study, nothing has been documented about women's impact on leadership in the education sector. This study serves as a basis for future deeper and broader examinations of the issue of women in educational leadership in the nation. It also opens the door to consider other sectors of civil society to ascertain the progress, successes, and challenges of women in leadership (Turamwishimiye, 2017).

Third, this investigation has provided the opportunity for a Western scholar to build relationships with scholars and leaders of Rwanda. In my experience, these studies serve to establish goodwill, serve as a basis for future initiatives and research, and provide much-needed understanding of the progress of women in leadership globally. This benefit is also aligned with the Ministry of Education's Higher Education Policy (2008), whose goal is to "support research, innovation, and knowledge transfer for sustainable development" (p. 19). The deeper and broader our understanding globally of challenges women leaders face, the greater the opportunity to remedy these.

Finally, and perhaps most significantly, an investigation of this nature has invited participants to share in their voices their stories of the successes and challenges of nation building. The publication and presentation of this work provide the larger global community with the opportunity to understand in more substantive ways the issues Rwanda faces and the solutions they offer, and to invite Rwandans to claim a voice on the world stage. While Rwandan women recognize clearly that there is no way to change the past and to erase the horror of the genocide, they remain committed

\section{REFERENCES}

Amnesty International (2018). Rwanda 2017/18. London, United Kingdom: Amnesty International Ltd. Available at: https:/www.amnesty.org/en/ countries/africa/rwanda/report-rwanda/.

Amnesty International (2021). Rwanda: More Progress Needed on Human Rights Commitments. London, UK: Amnesty International Ltd. Available at: https:// www.amnesty.org/download/Documents/AFR4728582020ENGLISH.PDF.

Badejo, D. I. (1998). African Feminism: Mythical and Social Power of Women of African Descent. Res. Afr. Literatures 29 (2), 94-111. Available at: https:// search.proquest.com/docview/207636177/fulltextPDF/A3E3F62A2264ADBPQ/ 1 ? accountid=7418.

Bernard, H. R. (2006). Research Methods in Anthropology. 4th Edn. Lanham, MD: AltaMira Press.

Bhola, H. S. (2002). Reclaiming Old Heritage for Proclaiming Future History: The Knowledge-for-development Debate in African Contexts. Africa Today 49 (3), 1-21. doi:10.2979/aft.2002.49.3.2

Burnet, J. E. (2008). Gender Balance and the Meanings of Women in Governance in Post-genocide Rwanda. Afr. Aff. 107 (428), 361-386. doi:10.1093/afraf/ $\operatorname{adn} 024$

Chabaya, O., Rembe, S., Rembe, S., and Wadesango, N. (2009). The persistence of Gender Inequality in Zimbabwe: Factors that Impede the Advancement of Women into Leadership Positions in Primary Schools. Saje 29, 235-251. doi:10.15700/saje.v29n2a259

Cheeseman, N., Onditi, F., and D'Alessandro, C. (2017). Introduction to the Special Issue: Women, Leadership, and Peace in Africa. Afr. Conflict Peacebuilding Rev. 7 (1), 1-17. doi:10.2979/africonfpeacrevi.7.1.01 to a future that will make a positive difference for their children.

\section{DATA AVAILABILITY STATEMENT}

The datasets generated for this study are not available due to protection of human subjects agreements with participants.

\section{ETHICS STATEMENT}

This study involving human participants was reviewed and approved by Loyola Marymount University Institutional Review Board, Rwanda National Ethics Committee, Ministry of Education of Rwanda, and University of Rwanda. The participants provided their written informed consent in order to participate.

\section{AUTHOR CONTRIBUTIONS}

ECR is solely responsible for the research investigation and for the production of this manuscript.

\section{SUPPLEMENTARY MATERIAL}

The Supplementary Material for this article can be found online at: https:/www.frontiersin.org/articles/10.3389/feduc.2021.561508/ full\#supplementary-material

Chilisa, B. (2009). "Indigenous African-centered Ethics: Contesting Complementing Dominant Models," in The handbook of Social Research Ethics. Editors D. Mertens and P. Ginsberg (Thousand Oaks, CA: SAGE), 407-425.

Chilisa, B. (2011). Indigenous Research Methodologies. Thousand Oaks, CA: SAGE.

Chilisa, B., and Ntseane, G. (2010). Resisting Dominant Discourses: Implications of Indigenous, African Feminist Theory and Methods for Gender and Education Research. Gend. Edu. 22 (6), 617-632. doi:10.1080/ 09540253.2010.519578

Clandinin, D. J., and Connelly, F. M. (2000). Narrative Inquiry: Experience and Story in Qualitative Research. San Francisco, CA: Jossey-Bass.

Clandinin, D. J. (2013). Engaging in Narrative Inquiry. Walnut Creek, CA: Left Coast Press Inc.

Clandinin, D. J., and Huber, J. (2010). "Narrative Inquiry," in International Encyclopedia of Education. Editors B. McGaw, E. Baker, and P. P. Peterson 3rd Edn. (Hillsdale, NJ: Lawrence Erlbaum), 375-385. doi:10.1016/b978-0-08044894-7.01387-7

Collins, P. H. (2000). Black Feminist Thought: Knowledge Consciousness and Politics of Empowerment. 2nd Edn. Oxfordshire, UK: Routledge.

Collins, P. H. (2009). "Toward an Afrocentric Feminist Epistemology," in Feminisms. Editors S. Kemp and J. Squires (Oxford, UK: Oxford University Press), 199-206.

Connelly, F. M., and Clandinin, D. J. (2006). "Narrative Inquiry," in Handbook of Complementary Methods in Education Research. Editors J. L. Green, G. Camilli, and P. Elmore 3rd Edn. (Mahwah, NJ: Lawrence Erlbaum).

Connelly, F. M., and Clandinin, D. J. (1990). Stories of Experience and Narrative Inquiry. Educ. Res. 19 (5), 2-14. doi:10.3102/0013189x019005002 
DeJaeghere, J. G., Williams, R., and Kyeyune, R. (2009). Ugandan Secondary School Headteachers' Efficacy: What Kind of Training for Whom?. Int. J. Educ. Dev. 29, 312-320. doi:10.1016/j.ijedudev.2008.03.001

Deji, O. F., and Makinde, O. T. (2006). Comparative Study of the Influence of Demographic and Socio-economic Characteristics of Men and Women Leaders on their Leadership Styles and Patterns in the Rural Areas of Nigeria. J. Comp. Soc. Welfare 22 (1), 49-62. doi:10.1080/17486830500523052

Dillard, C. M. (2009). "When the Ground is Black, the Ground is Fertile: Exploring Endarkened Feminist Epistemology and Healing Methodologies of the Spirit," in Handbook of Critical and Indigenous Methodologies. Editors M. Denzin, Y. Lincoln, and L. Smith (Thousand Oaks, CA: SAGE), 227-291.

Elabor-Idemudia, P. (2000). "The Retention of Knowledge of Folkways as a Basis for Resistance," in Indigenous Knowledge in Global Contexts. Editors G. Dei, B. Hall, and D. Rosenberg (Toronto, Canada: University of Toronto Press), 102-119.

Eltringham, N. (2004). Accounting for Horror: Post-genocide Debates in Rwanda. London, UK: Pluto Press.

Fennell, S., and Arnot, M. (2009). Decentralizing Hegemonic Gender Theory: The Implications for Educational Research. Development Studies and Faculty of Education, University of Cambridge. Cambridge, England, United Kingdom: University of Cambridge. Available at: https://ceid.educ.cam.ac.uk/ publications/WP21-MA_SF-final.pdf.

Gerstner, C. R., and Day, D. V. (1997). Meta-analytic Review of Leader-member Exchange Theory: Correlates and Construct Issues. J. Appl. Psychol. 82 (6), 827-844. doi:10.1037/0021-9010.82.6.827

Goduka, I. N. (2000). "African or Indigenous Philosophies; Legitimizing Spiritually Centered Wisdoms Within the Academy," in African Voices in Education. Editors P. Higgs, N. C. G. Vakalisa, T. V. Mda, and N. T. Assie-Lumumba (Capetown, South Africa: Juta and Co., Ltd), 63-83.

Gouws, A., and Kotzé, H. (2007). Women in Leadership Positions in South Africa: The Role of Values. Politikon 34 (2), 165-185. doi:10.1080/02589340701715273

Grogan, M. (2015). Women Leading Education (WLE): The Ghana Conference-Seeking New \& Deeper Understandings of Women's Leadership Across the Continents Special Collection. Plann. Changing J. 46 (3/4). Available at: https://education.illinoisstate.edu/planning/articles/ vol46.php.

Human Rights Watch (2020). Rwanda: Events of 2019. Available at: https://www. hrw.org/world-report/2020/country-chapters/rwanda.

Kagoda, A. M. (2015). "Barriers to Leadership and Challenges Faced by Female Heads in Educational Institutions in Uganda," in Women Leading Education Across the Continents: Overcoming the Barriers. Editors E. C. Reilly and Q. J. Bauer (Lanham, MD: Rowman \& Littlefield Education), 71-76.

Kagoda, A. M., and Sperandio, J. (2008). "Ugandan Women: Moving Beyond Historical and Cultural Understandings of Educational Leadership," in Women Leading Education Across the Continents: Sharing the Spirit, Fanning the Flame. Editor H. Sobehart (Lanham, MD: Rowman \& Littlefield Education), 49-56.

Kantengwa, M. J. (2010). The Will to Political Power: Rwandan Women in Leadership. IDS Bull. 41 (5), 72-80. doi:10.1111/j.1759-5436.2010.00168.x

Kigali Genocide Memorial (2016). Genocide Archive of Rwanda. Available at: https://genocidearchiverwanda.org.rw/index.php?title=Welcome_to_Genocide_ Archive_Rwanda.

Losike-Sedimo, N. (2017). "Theoretical Discussion of Gender and Power: The Case of the University of Botswana," in Information Resources Management Association Organizational Culture and Behavior: Concepts, Methodologies, Tools, and Applications. Editor IRMA (Hershey, PA: IGI Global), 69-84.

Lumby, J., and Azaola, C. (2011). Women Principals in Small Schools in South Africa. Aust. J. Edu. 55 (1), 73-85. doi:10.1177/000494411105500108

Lumby, J., and Azaola, M. C. (2014). Women Principals in South Africa: Gender, Mothering and Leadership. Br. Educ. Res. J. 40 (1), 30-44. doi:10.1002/berj.3028

Lumby, J., Azaola, M., de Wet, A-M., Skervin, H., Walsh, A., and Williamson, A. (2010). Women School Principals in South Africa: Leading the Way. Southampton, UK: University of Southampton. Available at: https://eprints. soton.ac.uk/189635/.

Lumby, J. (2015). “Theorizing Women Leaders' Experiences: Caught in the Web," in Women Leading Education Across the Continents: Overcoming the Barriers. Editors E. C. Reilly and Q. J. Bauer (Lanham, MD: Rowman \& Littlefield Education), 157-166.
Malachias, R., Reilly, E. C., and Fuller, K., (2018). "Women Leading Education: From Margins to Centers Collection," Periferia. 10. doi:10.12957/ periferia.2018.35868 Available at: http://www.e-publicacoes.uerj.br/index. php/periferia/issue/view/1769/showToc.

Mathipa, E. R., and Tsoka, E. M. (2001). Possible Barriers to the Advancement of Women to Leadership Positions in the Education Profession. South Afr. J. Edu. 21 (4), 324-331.

McNae, R., and Reilly, E. C. (2018). Women Leading Education Across the Continents: Harnessing the Joy in Leadership. (Lanham, MD: Rowman \& Littlefield Publishers).

Mekgwe, P. (2006). Theorizing African Feminism(s): The 'Colonial' Question. QUEST: Afr. J. Philos. 20 (1-2), 11-22.

Melvern, L. (2004). Conspiracy to Murder: The Rwandan Genocide. New York, NY: Verso.

Moodly, A. L. (2015). Gender Equity in South African Higher Education Leadership: Where are we Twenty Years After Democracy?. J. Soc. Sci. 42 (3), 229-238. doi:10.1080/09718923.2015.11893410

Moodly, A., and Toni, N. M. (2017). Accessing Higher Education Leadership: Towards a Framework for Women's Professional Development. South Afr. J. Higher Edu. 31 (3), 138-153. doi:10.208535/31-3-917

Moorosi, P. (2020). Constructions of Leadership Identities via Narratives of African Women School Leaders. Front. Educ. 5 (86). doi:10.3389/ feduc.2020.00086

Moorosi, P., Fuller, K., and Reilly, E. C. (2016). "A Comparative Analysis of Intersections of Gender and Race Among Black Female School Leaders in South Africa, United Kingdom and the United States," in Cultures of Educational Leadership: Global and Intercultural Perspectives. Editor P. Miller (London, UK: Palgrave Macmillan), 77-94. doi:10.1057/978-1-137-58567-7_4

Moorosi, P., Fuller, K., and Reilly, E. C. (2018). Leadership and Intersectionality: Constructions of Successful Leadership Among Black Women School Principals in Three Different Contexts. Manag. Edu. 32 (3), 334-353. doi:10.1177/0892020618791006

Moorosi, P., and Grant, C. (2018). The Socialisation and Leader Identity Development of School Leaders in Southern African Countries. Jea 56, 643-658. doi:10.1108/JEA-01-2018-0011

Moorosi, P. (2010). South African Female Principals' Career Paths: Understanding the Gender Gap in Secondary School Management. Educ. Manag. Adm. Leadersh. 38 (5), 547-562. doi:10.1177/1741143210373741

Moorosi, P. (2015). “"Breadwinners" and "Homemakers": How Constructions of Masculinities Affect Women's Progression in Leadership," in Women Leading Education Across the Continents: Overcoming the Barriers. Editors E. C. Reilly and Q. J. Bauer (Lanham, MD: Rowman \& Littlefield Education), 21-26.

Mpungose, J. (2010). Constructing Principals' Professional Identities Through Life Stories: An Exploration. Saje 30, 527-537. doi:10.15700/saje.v30n4a387

Newbury, C., and Baldwin, H. (2000). Aftermath: Women in Post Genocide Rwanda. Washington, DC: Center for Development Information and Evaluation, U.S. Agency for International Development. Available at: https://pdf.usaid.gov/pdf_docs/PNACJ323.pdf.

Nkomo, S. M., and Ngambi, H. (2009). African Women in Leadership: Current Knowledge and a Framework for Future Studies. Int. J. Afr. Renaissance Stud. Multi-, Inter-Transdisciplinarity 4 (1), 49-68. doi:10.1080/18186870903102014

Ntseane, P. G. (2009). Community Leadership and Empowerment: Botswana Case Study. Kampala: Institute of Social Transformation.

Nnameka, O.(1997). The Politics of Mothering: Womanhood, Identity and Resistance in African Literature (Oxfordshire, UK: Routledge).

Obura, A. (2003). Never Again: Educational Reconstruction in Rwanda. Paris, France: UNESCO. Available at: http://unesdoc.unesco.org/images/0013/ 001330/133051e.pdf.

Odhiambo, G. (2011). Women and Higher Education Leadership in Kenya: A Critical Analysis. J. Higher Edu. Pol. Manag. 33 (6), 667-678. doi:10.1080/ 1360080X.2011.621192

Phendla, T. (2008). "Women on the Rise. Women Navigating Across Social, Political, Economic and Cultural Arenas to Claim Their Stake in Educational Leadership Positions in South Africa," in Women Leading Education Across the Continents: Sharing the Spirit, Fanning the Flame. Editor H. Sobehart (Lanham, MD: Rowman \& Littlefield Education), 57-64. 
Prunier, G. (2009). Africa's World War: Congo, the Rwandan Genocide, and the Making of a Continental Catastrophe. Oxford, UK: Oxford University Press.

Randell, S. (2018). "Celebrating Leadership Learning in Education Across Continents: Experiences of Women Leading in Rwanda," in Women Leading Education Across the Continents: Finding and Harnessing the Joy in Leadership. Editors R. McNae and E. C. Reilly (Lanham, MD: Rowman \& Littlefield Education), 149-155.

Randell, S. (2009). Centre for Gender, Culture and Development 2009 Annual Report. Kigali, Rwanda: Kigali Institute of Education.

Rarieya, J. (2015). "Women Leading School in Challenging Contexts," in Women Leading Education Across the Continents: Overcoming the Barriers. Editors E. C. Reilly and Q. J. Bauer (Lanham, MD: Rowman \& Littlefield Education), 139-144.

Reilly, E. C. (2021). "Women in Educational Leadership Across Three Countries and Contexts: Reifying Socio-cultural Capital in Afghanistan, Costa Rica, and Rwanda," in The Handbook for Gender and Educational Leadership. Editors V. Showunmi, C. Shakeshaft, P. Moorosi, and I. Oplatka (London, UK: Bloomsbury).

Reilly, E. C., and Bauer, Q. (Editors) (2015). Women Leading Education Across the Continents: Overcoming the Barriers. (Lanham, MD: Rowman \& Littlefield Publishers.)

Republic of Rwanda Ministry of Education (2019). 2019 Educational Statistics. Available at: https://www.mineduc.gov.rw/fileadmin/user_upload/Mineduc/ Publications/EDUCATION_STATISTICS/01_Rwanda_Education_Statistics2019.pdf.

Republic of Rwanda Ministry of Education (2018). Education Sector Strategic Plan 2018/19 to 2023/24. Available at: https://www.mineduc.gov.rw/fileadmin/user_ upload/Mineduc/Publications/ESSP/1_Education_Sector_Strategic_Plan_ 2018_2024.pdf.

Republic of Rwanda Ministry of Education (2008). Higher Education Policy. Available at: https://www.mineduc.gov.rw/fileadmin/user_upload/Mineduc/ Publications/POLICIES/Higher_Eduation_Policy.pdf.

Republic of Rwanda Ministry of Education (2013). National Financial Education Strategy for Rwanda. Available at: https://nanopdf.com/download/nationalfinancial-education-strategy-for-rwanda_pdf.

Republic of Rwanda Ministry of Education (2012). Rules and Regulations for Research in Rwanda. Available at: http://www.ncst.gov.rw/sites/default/files/ laws/Research_Rules_and_Regulations.pdf.

Republic of Rwanda Ministry of Finance and Economic Planning (2020). Vision 2020. Available at: https://www.greengrowthknowledge.org/sites/default/files/ downloads/policy-database/RWANDA\%29\%20Rwanda\%20Vision\%202020.pdf.

Sobehart, H. (2009). Women Leading Education Across the Continents: Sharing the Spirit, Fanning the Flame. (Lanham, MD: Rowman \& Littlefield Publishers).

Sperandio, J. (2000). Leadership for Adolescent Girls: The Role of Secondary Schools in Uganda. Gend. Dev. 8 (3), 57-64. doi:10.1080/741923781

Sperandio, J., and Merab Kagoda, A. (2010). Women Teachers' Aspirations to School Leadership in Uganda. Intl Jnl Educ. Mgt 24 (1), 22-33. doi:10.1108/ 09513541011013024

Steady, F. C. (2011). Women and Leadership in West Africa: Mothering the Nation and Humanizing the State. London, UK: Palgrave Macmillan.

Taylor, C. C. (1999). "The Cultural Face of Terror in the Rwandan Genocide of 1994," in Annihilating Differences: The Anthropology of Genocide. Editor A. L. Hinton (Berkeley, CA: University of California Press), 137-179.

Thompson, S. (2014). Rwanda's National Unity and Reconciliation Program. EInternational Relations. Available at: https://www.e-ir.info/2014/05/01/ rwandas-national-unity-and-reconciliation-program/.

Tom Lantos Human Rights Commission, United States Senate (2018). Rwanda: Human Rights and Political Prisoners. Washington, DC. Available at: https:// humanrightscommission.house.gov/events/hearings/rwanda-human-rights-andpolitical-prisoners.
Turamwishimiye, M-R. (2017). The Role of African Women in Post-conflict National Development: The Case of Rwanda. Kigali, Rwanda: University of Rwanda.

UNESCO (2007). Country Programming Document: Rwanda 2007-2008. Available at: http://unesdoc.unesco.org/images/0015/001546/154676e.pdf.

United Nations Committee on the Elimination of Discrimination Against Women (2017). Rwanda and United Nations Treaty Bodies: Concluding Observations. New York, NY. Available at: https://tbinternet.ohchr.org/_layouts/15/ treatybodyexternal/Download.aspx?symbolno=CEDAW/C/RWA/CO/79\&Lang=En.

United States Department of Health and Human Services (2012). International Compilation of Human Research Standards. Washington, DC. Available at: http://www.hhs.gov/ohrp/international/intlcompilation/intlcompilation.html.

United States Department of State (2014). 2013 Human Rights Report: Rwanda. Washington, DC. Available at: http://www.state.gov/j/drl/rls/hrrpt/2009/af/ 135971.htm.

University of Rwanda (2020). Facts and Figures 2013-2020: Seven Years Thematic Statistical Report. Available at: https://ur.ac.rw/IMG/pdf/ff-2020-final_version_ b-2.pdf.

University of Rwanda (2016). Gender Policy. Available at: https://ur.ac.rw/ documents/UR\%20Gender\%20Policy.compressed.pdf.

USAID (2020). Rwanda: Country Development Cooperation Strategy. Available at: https://www.usaid.gov/sites/default/files/documents/1860/CDCS_Rwanda_ February_2025_2.pdf.

Wane, N. (2011). "African Indigenous Feminist Thought," in The Politics of Cultural Knowledge. Editors N. N. Wane, A. Kempf, and M. Simmons (Leiden, Netherlands: Brill), 7-21. doi:10.1007/978-94-6091-481-2_2

Williamson Sinalo, C. (2018). Rwanda After Genocide: Gender, Identity and Posttraumatic Growth. Cambridge, UK: Cambridge University Press. doi:10.1017/ 9781108591478Rwanda after Genocide

Wilson-Tagoe, J. E. (2015). "Empowering Female Faculty in Ghana's Public Universities: Mentoring a Door Opener in the University of Education, Winneba, and University of Cape Coast, Ghana," in Women Leading Education Across the Continents: Overcoming the Barriers. Editors E. C. Reilly and Q. J. Bauer (Lanham, MD: Rowman \& Littlefield Education), 91-96.

Women Leading Education (2021). Women Leading Education. Available at: http://www.thewle.com/about-1.html.

World Bank (2020). Learning for All: Investing in People's Knowledge and Skills to Promote Development. Available at: https://pubdocs.worldbank.org/en/ 418511491235420712/Education-Strategy-4-12-2011.pdf.

World Bank (2019). The World Bank in Rwanda. Available at: https://www. worldbank.org/en/country/rwanda/overview.

Conflict of Interest: The author declares that the research was conducted in the absence of any commercial or financial relationships that could be construed as a potential conflict of interest.

Publisher's Note: All claims expressed in this article are solely those of the authors and do not necessarily represent those of their affiliated organizations, or those of the publisher, the editors and the reviewers. Any product that may be evaluated in this article, or claim that may be made by its manufacturer, is not guaranteed or endorsed by the publisher.

Copyright $\odot 2021$ Reilly. This is an open-access article distributed under the terms of the Creative Commons Attribution License (CC BY). The use, distribution or reproduction in other forums is permitted, provided the original author(s) and the copyright owner(s) are credited and that the original publication in this journal is cited, in accordance with accepted academic practice. No use, distribution or reproduction is permitted which does not comply with these terms. 